\title{
The use of fermentation for rational processing of fish: a review
}

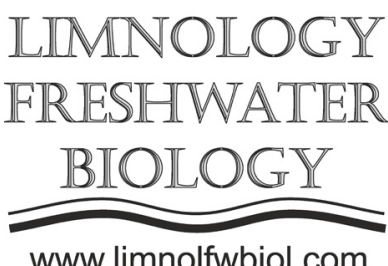

www.limnolfwbiol.com

\begin{abstract}
Nikiforova A.P.
East Siberia State University of Technology and Management, Klyuchevskaya Str., 40 “v”, building 1, Ulan-Ude, 670013, Russia

ABSTRACT. Fermentation is widely used for conservation of food products. In many regions of the world fermentation is used for production of large amount of fish processing by-products that are currently being disposed or used for production of low-value products. There is a large potential for reducing the amount of by-products and utilizing a larger amount of fish processing by-products for high value products.

With the use of fermentation, it can be possible to produce a broad spectrum of food products as well as food ingredients for wide range of applications.

Therefore, the main aim of the study is to perform the analysis of literature sources on the use of fermentation for rational fish processing.
\end{abstract}

Keywords: fermentation, fish by-products, enzymes, bacterial strains

\section{Introduction}

Fermentation plays an important role in many parts of the world for the production of traditional fish products. In some regions of the world, especially in Asia, fermented food is popular among tourists and local people and is widely used as a component of daily diet.

Enzymes are key tools in biotechnology (Fraatz et al., 2014). Accordingly, they have been used in food technology and processing since ancient times for production of a range of products (Fernandes, 2016).

Enzymes that are present in fish together with some halotolerant and halophilic microorganisms are important for fish fermentation. They are responsible for formation of characteristic odor, flavor and taste. The enzymatic action leads to protein and lipid breakdown and formation of fatty acids, amino acids and peptides.

One of the most important problems of fish industry is underutilization and seafood waste. It is known that large amount of fish by-products is currently disposed or used for low-value products. There is a large potential for reducing the amount of by-products and utilizing a larger amount of the by-products for value added products for human consumption (Muzaifa et al., 2012).

Thus, the study of ways of rational fish processing with the use of fermentation is an object of great interest.

\section{Materials and methods} article.

The review of literature was performed in the

\section{Results and Discussion}

In the recent years the processing of fish with the use of fermentation is increasing (Fernandes, 2016). Many scientific works have been devoted to the use of fermentation (with the use of enzymes or bacteria) for rational fish processing.

Fermented fish products are widely produced in many regions of the world, including Asia, Northern Europe, Africa and others. For example, fermented fish products 's dushkom', produced from Baikal omul, is a local specialty of Baikal region of Russia (Nikiforova et al., 2019). Mostly, spontaneous fermentation is used for production of traditional fermented fish products. To avoid spontaneous fermentation which is not controllable and can increase the risk of foodborne illnesses the fermentation with the use of bacterial cultures can be a good solution (Speranza et al., 2015). In addition, fermentation of fish with bacterial cultures can be beneficial to formation of necessary organoleptic characteristics of fish products.

Another product made from fish is fish protein hydrolysates. For its production enzymatic or chemical hydrolysis can be used. Protein hydrolysates are rich in protein and can be used in any ways. For example, as a

*Corresponding author.

E-mail address: anna.p.nikiforova@gmail.com (A.P. Nikiforova) 


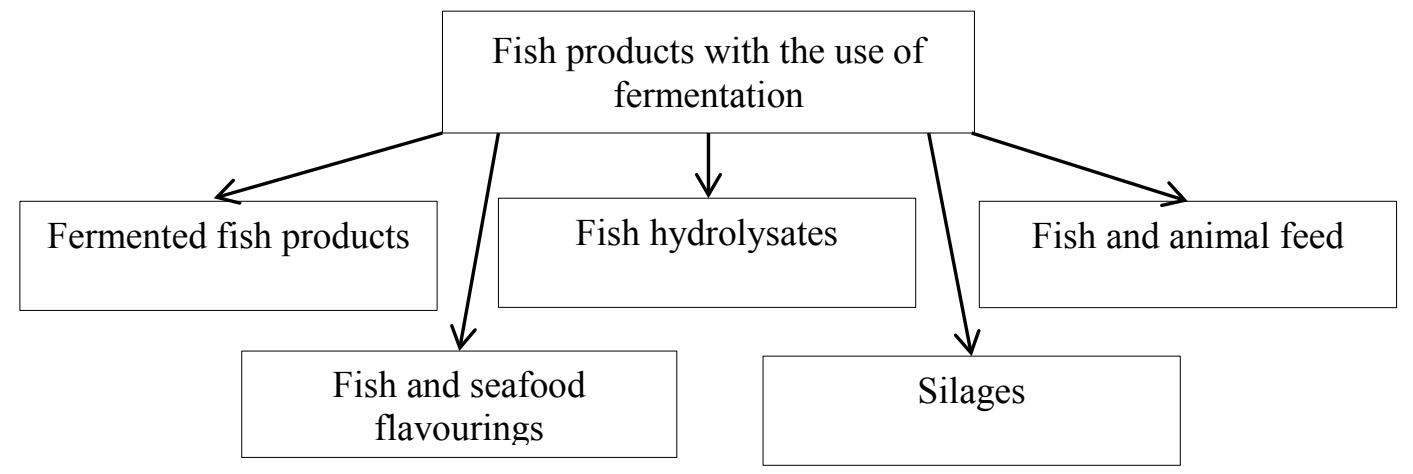

Fig. Fish products produced with the use of fermentation

component of bacterial culture media or as medication for treatment of cardiovascular, dermatological, neurological, and metabolic diseases (Gevaert et al., 2016).

The use of fermentation for the production of fish and animal feeds has been reported before (Hassan and Heath, 1986; Dawood and Koshio, 2020).

Another important way of use of fish waste is production of fish and seafood flavourings. The conversion of low value fish derived materials into more valuable products such as flavor precursors and subsequently flavor compounds might be a commercially viable proposition for the fish industry (Peinado et al., 2016)particularly for leucine, lysine and glutamic acid (48.3 \pm 3.4 to $1423.4 \pm 59.6,43.3$ \pm 1.2 to $1485.4 \pm 25.6$ and $143.6 \pm 21.7$ to $980.9 \pm$ $63.6 \mu \mathrm{g} / \mathrm{g}$ respectively.

It is known that silages can be produced from fish and fish offal. For instance, in the work of Lindgren and Pleje the use of Pediococcus acidilactici and Lactobacillus plantarum for silage production has been studied (Lindgren and Pleje, 1983).

The scheme, which shows fish products produced with the use of fermentation, is presented below (Fig.).

\section{Conclusions}

By the use of fermentation, it may be possible to produce a broad spectrum of food ingredients for wide range of applications.

\section{Acknowledgements}

This work was supported by a grant of the President of Russian Federation for young Russian scientists (MK-128.2020.11)

\section{References}

Dawood M.A.O., Koshio S. 2020. Application of fermentation strategy in aquafeed for sustainable aquaculture. Reviews in Aquaculture 12: 987-1002. DOI: 10.1111/ raq.12368

Fernandes P. 2016. Enzymes in fish and seafood processing. Frontiers in Bioengineering and Biotechnology 4. DOI: 10.3389/fbioe.2016.00059

Fraatz M.A., Rühl M., Zorn H. 2014. Food and feed enzymes. Advances in Biochemical Engineering/ Biotechnology 143: 229-256. DOI: 10.1007/10_2013_235

Gevaert B., Veryser L., Verbeke F. et al. 2016. Fish hydrolysates: a regulatory perspective of bioactive peptides. Protein and Peptide Letters 23: 1052-1060. DOI: 10.2174/09 29866523666161102122637

Hassan T.E., Heath J.L. 1986. Biological fermentation of fish waste for potential use in animal and poultry feeds. Agricultural Wastes 15: 1-15. DOI: 10.1016/0141-4607(86)90122-8

Lindgren S., Pleje M. 1983. Silage fermentation of fish or fish waste products with lactic acid bacteria. Journal of the Science of Food and Agriculture 34: 1057-1067. DOI: 10.1002/jsfa.2740341005

Muzaifa M., Safriani N., Zakaria F. 2012. Production of protein hydrolysates from fish by-product prepared by enzymatic hydrolysis. AACL Bioflux 5: 36-39.

Nikiforova A., Zamaratskaia G., Pickova J. 2019. Fatty acid composition of salted and fermented products from Baikal omul (Coregonus autumnalis migratorius). Journal of Food Science and Technology 57: 595-605. DOI: 10.1007/ s13197-019-04091-z

Peinado I., Koutsidis G., Ames J. 2016. Production of seafood flavour formulations from enzymatic hydrolysates of fish by-products. LWT - Food Science and Technology 66: 444-452. DOI: 10.1016/j.lwt.2015.09.025

Speranza B., Racioppo A., Bevilacqua A. et al. 2015. Selection of autochthonous strains as starter cultures for fermented fish products. Journal of Food Science 80: M151M160. DOI: 10.1111/1750-3841.12721 